\title{
When Imagining Yourself in Pain, Visual Perspective Matters: The Neural and Behavioral Correlates of Simulated Sensory Experiences
}

\author{
Brittany M. Christian ${ }^{1 *}$, Carolyn Parkinson ${ }^{2 *}$, C. Neil Macrae ${ }^{3}$, \\ Lynden K. Miles ${ }^{3}$, and Thalia Wheatley ${ }^{2}$
}

\begin{abstract}
Via mental simulation, imagined events faithfully reproduce the neural and behavioral activities that accompany their actual occurrence. However, little is known about how fundamental characteristics of mental imagery-notably perspectives of selfshape neurocognitive processes. To address this issue, we used fMRI to explore the impact that vantage point exerts on the neural and behavioral correlates of imaginary sensory experiences (i.e., pain). Participants imagined painful scenarios from three distinct visual perspectives: first-person self (1PS), third-person self (3PS),
\end{abstract}

\section{INTRODUCTION}

Imagination is a powerful tool. Not only does it facilitate the contemplation of a world beyond the here-and-now, it also has the ability to alter present reality (e.g., changing current psychological and physiological states). Indeed, figments of the imagination can provoke paralyzing fear, irresistible temptation, or overwhelming joy. Through this capacity to imagine events in a realistic manner, prospective experiences can be previewed (i.e., analyzed, evaluated) and behavior can be optimized to meet the myriad demands of daily living (Boyer, 2008; Gilbert \& Wilson, 2007; Suddendorf \& Corballis, 2007; Wilson \& Gilbert, 2003). To this end, people spend considerable amounts of time simulating, rather than directly perceiving, the world around them (Killingsworth \& Gilbert, 2010; Smallwood \& Schooler, 2006). Guided by the combined influence of semantic and episodic memory (Szpunar, 2010; Addis, Wong, \& Schacter, 2007; Buckner \& Carroll, 2007; Schacter, Addis, \& Buckner, 2007), these mental simulations provide invaluable insight into the character and potential consequences of yet-to-be experienced events.

Underlying the functional nature of mental simulations are the overlapping neurocognitive operations that support both imagination and perception/action (Moulton \& Kosslyn, 2009; Kosslyn \& Moulton, 2009; Kosslyn, Ganis, \& Thompson, 2006; Gallese, 2005; Fadiga \& Craighero, 2004;

${ }^{1}$ University of Chicago, ${ }^{2}$ Dartmouth College, ${ }^{3}$ University of Aberdeen *Denotes equal author contribution. and third-person other (3PO). Corroborating increased ratings of pain and embodiment, 1PS (cf. 3PS) simulations elicited greater activity in the right anterior insula, a brain area that supports interoceptive and emotional awareness. Additionally, 1PS simulations evoked greater activity in brain areas associated with visual imagery and the sense of body ownership. Interestingly, no differences were observed between 3PS and 3PO imagery. Taken together, these findings reveal the neural and behavioral correlates of visual perspective during mental simulation.
Ganis, Thompson, \& Kosslyn, 2004; Grèzes \& Decety, 2001; Jeannerod, 2001; Kosslyn, Ganis, \& Thompson, 2001; Farah, 1989). For example, imagining an unpleasant ordealsuch as root canal work at the dentist - can elicit physical and psychological effects (e.g., elevated heart rate, pain, anxiety) commensurate with the veridical event (i.e., mental simulation is embodied; see Meier, Schnall, Schwartz, \& Bargh, 2012; Holmes \& Mathews, 2010; Niedenthal, Barsalou, Winkielman, Krauth-Gruber, \& Ric, 2005; Wilson, 2002; Barsalou, 1999; Arnold, 1984). According to this viewpoint, mental simulation is enabled via sensorimotor activity that evolved to support interaction with the environment (Suddendorf \& Corballis, 2007; Decety, 1996; Jeannerod, 1994). Importantly, however, a robust body of evidence suggests that the "target" (i.e., self vs. other) of the simulation modulates the extent to which imaginary experiences recruit the same neural mechanisms that support veridical experience (Ochsner et al., 2008; Zaki, Ochsner, Hanelin, Wager, \& Mackey, 2007; Jackson, Brunet, Meltzoff, \& Decety, 2006; Jackson, Meltzoff, \& Decety, 2005; Decety \& Jackson, 2004; Ochsner et al., 2004; Singer et al., 2004).

When imagining another individual's experience, too little overlap with the neural and cognitive activities that support perception/action can impede social-cognitive functions and undermine empathic accuracy (Uddin et al., 2008; Decety \& Jackson, 2006). At the same time, however, neural and behavioral distinctions between targets are necessary to maintain a sense of agency as well as the functional integrity of mental simulation (Decety 
\& Jackson, 2006). As such, when participants imagine themselves performing a simple action, there is greater activity in the neural substrates that underlie actual performance, compared with simulations of another person (e.g., the experimenter) executing the same movements (Ruby \& Decety, 2001). Moreover, beyond straightforward motor behavior, a number of experiments have shown that the activation of brain regions implicated in sensory perception is greater for self- compared with other simulations (Jackson et al., 2005, 2006; Ruby \& Decety, 2001). In particular, the anterior insula (AI), an area of the brain that is crucial to the awareness of subjective feeling states (e.g., pain, thirst, arousal; see Zaki, Davis, \& Ochsner, 2012; Lamm \& Singer, 2010; Craig, 2002, 2003, 2009; Critchley, 2004, 2005, 2009; Singer, Critchley, \& Preuschoff, 2009; Critchley, Wiens, Rotshtein, Ohman, \& Dolan, 2004), is preferentially recruited during self-simulations (Jackson et al., 2006). Consistent with this pattern of activation, assessments of the intensity of others' experiences are generally subdued compared with our own (e.g., my pain is worse than your pain).

One possible explanation for these findings is that, being body-centered and agentic, self-simulations recruit more pronounced sensorimotor processes than comparable other-person musings (Jackson et al., 2006). Evidence to support this claim reveals that viewing actions from a body-congruent perspective elicits greater activity in the sensorimotor cortex compared with watching them from an incongruent orientation (Jackson et al., 2006). Elsewhere, investigations have indicated that agency and body ownership rely heavily on sensorimotor inputs being collated from a first-person frame of reference (Petkova, Khoshnevis, \& Ehrsson, 2011). When body-congruent visual cues are in place, people have been shown to take ownership over rubber hands and even feel vicariously responsible for other people's actions (Costantini \& Haggard, 2007; Ehrsson, Spence, \& Passingham, 2004; Wegner, Sparrow, \& Winerman, 2004; Pavani, Spence, \& Driver, 2000). Taken together, these findings suggest that visuospatial information (e.g., body congruent vs. body incongruent) may be an important referent for distinguishing between self and other (Decety \& Jackson, 2006).

Curiously, however, in the mental world, the self can be and, in fact quite commonly, is viewed from an outside point of view (Christian, Miles, Parkinson, \& Macrae, 2013), with approximately $46 \%$ of individuals indicating that a third-person perspective is their predominate mode of imagery in everyday life. When adopting a third-person (i.e., observer) perspective, people see themselves embedded in an event, as if from an external viewpoint (Libby \& Eibach, 2011; Nigro \& Neisser, 1983). In contrast, from a first-person (i.e., actor) vantage point, people simulate events through their own eyes, as if they are looking outward on the environment. As Nigro and Neisser pointed out when they originally identified the prevalence of first(i.e., field) and third-person (i.e., observer) perspectives in episodic memory, these distinct vantage points empha- size different aspects of an event during mental simulation. Whereas first-person simulations contain more information pertaining to bodily sensations, affective reactions, and psychological states (e.g., Holmes \& Mathews, 2010; McIsaac \& Eich, 2002, 2004; Nigro \& Neisser, 1983), thirdperson simulations tend to focus on the overarching purpose of an action and lack specific experiential details (Libby \& Eibach, 2011). In other words, at a behavioral level, firstperson simulations are more embodied than their thirdperson counterparts (Miles, Christian, Masilamani, Volpi, \& Macrae, 2014; Macrae, Sunder Raj, Best, Christian, \& Miles, 2013). Evidence for distinct neural mechanisms that underlie the retrieval of everyday autobiographical events (e.g., making a sandwich, following a map) from a first-person versus a third-person point of view (Eich, Nelson, Leghari, \& Handy, 2009) substantiates this claim. When it comes to previewing imaginary sensory experiences (e.g., pain), however, the neural mechanisms that support these modes of simulation have yet to be investigated. ${ }^{1}$

\section{Current Research}

To identify the neural operations that accompany hypothetical self-simulations generated from first- and thirdperson points of view, the current experiment used fMRI to measure the BOLD response to imaginary sensory experiences across three distinct visual perspectives: firstperson self (1PS), third-person self (3PS), and third-person other (3PO). In recent years, many studies exploring (BOLD) responses to imaginary painful experiences have yielded activity in regions of the putative pain matrix (Derbyshire, 2000) and corroborated the role of the AI as a key component of interoceptive awareness (Van der Heiden, Scherpiet, Konicar, Birbaumer, \& Veit, 2013; Lamm, Decety, \& Singer, 2011; Singer \& Lamm, 2009; Hein \& Singer, 2008; Ochsner et al., 2008; Zaki et al., 2007; de Vignemont \& Singer, 2006; Jackson et al., 2005, 2006; Lawrence et al., 2006). For this reason, simulated pain was utilized here as a vehicle to investigate the impact of vantage point on the patterns of BOLD responses elicited by imagined sensory experiences.

Given that no previous neuroimaging studies have considered imagining hypothetical sensory experiences from a 3PS perspective, the current design enabled two previously unexplored contrasts to be undertaken: (i) 1PS versus 3PS to determine the role of body-centered versus non-body-centered self-relevant imagery and (ii) 3PS versus $3 \mathrm{PO}$ to investigate potential differences between self- and other simulations when both are visualized from a thirdperson frame of reference. Guided by the growing body of evidence, which posits that self-simulations from a first-person perspective are imbued with more experiential content than the third-person equivalents (Macrae et al., 2013, 2014; Miles et al., 2014; Eich et al., 2009; McIsaac \& Eich, 2002, 2004; Nigro \& Neisser, 1983), we expected recruitment of neural areas that support interoceptive awareness (e.g., AI) to be greater when sensory experi- 
ences were imagined from a 1PS than 3PS perspective. Differences were also expected to emerge in other cortical regions associated with mental simulation (Eich et al., 2009; Moulton \& Kosslyn, 2009). Specifically, temporal-parietal regions implicated in body awareness and action representation were anticipated to yield greater activity when events were generated from a 1PS (cf. 3PS) vantage point (e.g., Tsakiris, 2010; Blanke et al., 2005; Decety \& Sommerville, 2003; Blanke, Ortigue, Landis, \& Seeck, 2002; Chaminade \& Decety, 2002; Farrer \& Frith, 2002). Considering the scarcity of work addressing self- versus other imagery from a third-person perspective, we adopted an exploratory approach when comparing these modes of simulation. In keeping with previous work on selfreferential processing, however, one possibility is that differences may emerge in medial prefrontal cortex (MPFC) as a function of the simulated target (i.e., 3PS > 3PO; Wagner, Haxby, \& Heatherton, 2012; Kelley et al., 2002).

\section{METHODS}

\section{Participants and Design}

Thirty-three right-handed adults $\left(M_{\text {age }}=19.7\right.$ years, $S D=$ 2.8 ; 18 women) participated in the experiment in exchange for $\$ 25$ or course credit. All participants were fluent in English and had normal or corrected-to-normal vision. They reported the imagery perspective they most frequently adopt and completed the Vividness of Visual Imagery Questionnaire (VIQ; Marks, 1973) to ensure they were able to generate sufficiently clear mental simulations to perform the task. ${ }^{2}$ The study was reviewed and approved by the Committee for the Protection of Human Subjects at Dartmouth College and had a single factor (Visual Perspective: 1PS vs. 3PS vs. 3PO) repeated-measures design.

\section{Materials and Procedure}

Participants engaged in a series of guided mental imagery tasks from three distinct visual perspectives (i.e., 1PS, 3PS, 3PO). Specifically, participants were instructed to imagine everyday painful episodes (e.g., cut finger) that were (i) happening to themselves and seen from a first-person point of view (i.e., through their own eyes), (ii) happening to themselves and seen from a third-person point of view (i.e., as if they were seeing themselves from an external viewpoint), and (iii) happening to an unfamiliar other person and seen from a third-person point of view (i.e., akin to how we would see someone else in pain in everyday life). ${ }^{3}$ The materials were adapted from Jackson et al. (2006) and before scanning the experimenter described all aspects of the procedure (e.g., the three visual perspectives) to ensure participants' understanding of the task.

\section{fMRI Design}

Participants imagined 10 pain-eliciting scenarios from a single perspective before moving on to another vantage point. A block design was used to minimize switching costs associated with changing perspective. All three perspectives were presented in each run (perspective order counterbalanced across runs; run order counterbalanced across participants), such that every run comprised 30 scenarios. There were three runs in total, thus each participant imagined a total of 90 painful experiences. At the beginning of each block, participants were shown a set of instructions informing them which visual perspective (with an accompanying description) they were to adopt for the next 10 trials. On each trial, participants saw a short prompt reminding them of the perspective they were required to use for the upcoming scenario (e.g., first-self), followed by a brief description of the painful episode (e.g., stub toe on door), which was displayed for 2500 msec before disappearing to reveal a blank gray screen that remained for 5000 msec. Participants were instructed to imagine the prompted scenario from the appropriate perspective as clearly and vividly as possible during the blank screen. Following each trial, participants were required to give ratings about their imagery experience. On a 5-point scale, they responded to how vivid ( $1=$ not very vivid, $5=$ very vivid $)$ and painful $(1=$ not very painful, $5=$ very painful $)$ they imagined the experience to be (either for themselves or the unfamiliar other). Given that participants received the same instructions and performed the same rating task on all trials within all blocks, linguistic and motoric processing demands associated with making ratings were matched between blocks corresponding to different imagery conditions.

\section{Postimaging Procedure}

After the scanning session, participants reported the difficulty they had experienced adopting each of the visual perspectives (9-point scale: $1=$ not difficult, $9=$ very difficult) and filled out a detailed questionnaire (adapted from Lenggenhager, Mouthon, \& Blanke, 2009) that assessed the level of disembodiment associated with each vantage point. For example, participants were asked, "How strong was the feeling that you were experiencing the painful scenarios you imagined?" and "How strong was the feeling that you were located at some distance away from where the painful scenario was taking place?" These questions tapped into how much participants felt physically, as well as emotionally, distanced from pain in the imagined scenario. Finally, participants were debriefed and dismissed.

\section{Imaging Acquisition and Analysis}

Images were acquired using a Philips Intera Achieva 3-T Scanner (Philips Medical Systems, Bothell, WA) with a 32-channel SENSE (SENSEitivity Encoding) head coil. Stimuli were presented via a Panasonic DT-4000UI DLP projector connected to a Macbook Pro laptop running 
SuperLab 4.0 (San Pedro, CA). Functional images in pain imagery runs were collected using gradient-echo echoplanar imaging (echo time/repetition time $=35 / 2500 \mathrm{msec}$; voxel resolution $=3 \mathrm{~mm} \times 3 \mathrm{~mm} \times 3 \mathrm{~mm}$; field of view $=$ $240 \mathrm{~mm} \times 240 \mathrm{~mm}$; matrix size $=80 \times 80$ ) with forty-two 3 -mm thick transverse slices (no gap) acquired in interleaved order. Each functional run consisted of 269 dynamic scans, giving a total scan duration of $11^{\prime} 22^{\prime \prime}$ per run. A highresolution T1-weighted anatomical image was acquired at the end of the scanning session (220 slices; echo time/ repetition time $=3.7 / 8200 \mathrm{msec}$; voxel resolution $=$ $0.94 \mathrm{~mm} \times 0.94 \mathrm{~mm} \times 1.00 \mathrm{~mm}$; field of view $=240 \mathrm{~mm} \times$ $188 \mathrm{~mm}$; acquisition matrix size $=240 \times 187$; total acquisition time $=3 \mathrm{~min}$ and $7 \mathrm{sec}$ ).

Data were preprocessed and analyzed using AFNI (Cox, 1996). Extreme signal changes not attributable to physiological phenomena were removed using the AFNI program $3 \mathrm{dDespike.} \mathrm{Slice} \mathrm{timing} \mathrm{correction} \mathrm{was} \mathrm{applied} \mathrm{to} \mathrm{each}$ volume to adjust for interleaved slice acquisition order. To correct for head motion, each functional volume was spatially aligned to the volume acquired closest in time to the anatomical scan (i.e., to the final volume of the last functional run), then aligned to the anatomical scan using the AFNI program 3dvolreg. Data were spatially smoothed with a Gaussian $6 \mathrm{~mm}$ FWHM kernel using the AFNI program 3 dmerge, and each voxel time series was scaled to have a mean of 100. Before regression, consecutive repetition time pairs where the Euclidean norm of the motion derivative exceeded 1.0 were excluded from further analysis.

The average voxel-wise hemodynamic response for each imagery condition (1PS, 3PS, 3PO) was estimated using the AFNI program $3 \mathrm{dDeconvolve.} \mathrm{Each} \mathrm{imagery}$ block was modeled by a block function with 200-sec duration. The six demeaned motion parameters obtained from 3 dvolreg were also included as predictors of no interest, and data were detrended with a fourth-order polynomial to account for signal changes because of scanner drift and head motion. Each participant's anatomical scan was skull-stripped and transformed to standard space using the AFNI program @auto_tlrc, and the same transform was used to align each participant's functional results to standard space before group analysis. In order to restrict analyses to cortex, a relatively liberal gray matter mask of the TT_N27 brain was created using FMRIB's Automated Segmentation Tool (Zhang, Brady, \& Smith, 2001) in FSL (Smith et al., 2004) and dilated using the 3 dcalc function in AFNI.

Dissociating the effects of vantage point and target identity on fMRI responses during mental simulations required two key statistical contrasts. First, to probe for regions in which activity was modulated by the visual perspective adopted while imagining self, responses to 1PS and 3PS were compared using the AFNI program $3 \mathrm{dttest}++$. Centered difficulty ratings for each condition were included as a covariate of no interest to control for any differences in brain activity between the two conditions attributable to task difficulty. Second, to probe for regions in which activity was modulated by the identity of the imagined target (i.e., self/other differences) in the absence of differences in visual perspective, an analogous analysis was undertaken to compare neural responses to 3PS and $3 \mathrm{PO}$. In order to integrate the current findings into the extant perspective-taking literature, we also explored differences between 1PS and 3PO imagery.

Correction for multiple comparisons was carried out using 3dClustSim in AFNI, which implements Monte Carlo simulations $(n=1000)$ to determine the combined voxel intensity and cluster extent thresholds required to establish a family-wise false positive rate of $5 \%$. The spatial structure of the noise in each participant's data was estimated by applying AFNI's $3 \mathrm{dFWHMx}$ function to each participant's residuals following subtraction of the GLMfitted signal model from voxel-wise time series data. The resultant spatial smoothness estimates were averaged across participants and input into $3 \mathrm{dClustSim}$ along with the data set mask used for analysis. The results of this procedure indicated that a voxel-wise threshold of $p<.02$ and a cluster extent threshold of eighty-seven $3 \mathrm{~mm} \times$ $3 \mathrm{~mm} \times 3 \mathrm{~mm}$ voxels would provide a family-wise error (FWE) rate of .05 . All reported results are significant according to these criteria (i.e., at an FWE-corrected threshold of $p<.05$ ).

\section{RESULTS}

\section{Behavioral Data}

To explore the effects of vantage point on participants' behavioral data, ratings of pain, vividness, disembodiment, and difficulty were each submitted to a single factor (Visual Perspective: 1PS, 3PS, 3PO) repeated-measures ANOVA. ${ }^{4}$ The results revealed an effect of visual perspective on ratings of pain, $F(2,64)=7.31, p=.001, \eta_{\mathrm{p}}{ }^{2}=$ 0.19 (see Figure 1A), vividness, $F(2,64)=10.58, p<$ $.05, \eta_{\mathrm{p}}{ }^{2}=0.25$ (see Figure 1B), disembodiment, $F(1.61$, $51.51)=32.48, p<.001, \eta_{\mathrm{p}}{ }^{2}=0.50$ (see Figure $1 \mathrm{C}$ ) and difficulty, $F(1.71,54.62)=21.88, p<.001, \eta_{\mathrm{p}}^{2}=0.41$ (see Figure 1D). Post hoc $t$ tests (Bonferroni-corrected) revealed that imagined episodes were considered to be more painful, $t(32)=2.70, p=.02, d=0.30$, and vivid, $t(32)=4.41, p<.001, d=0.61$, when simulated from a 1PS compared with a 3PS perspective. In addition, mental imagery was rated as less disembodied, $t(32)=-7.18$, $p<.001, d=1.27$, and easier to generate, $t(32)=-8.14$, $p<.001, d=1.94$, when imagined from a 1PS than 3PS viewpoint. An identical pattern of results was seen when comparing 1PS to $3 \mathrm{PO}$ for behavioral ratings of pain, $t(32)=3.25, p<.01, d=0.36$, and vividness, $t(32)=$ $3.60, p<.01, d=0.44$, (i.e., 1 st $>3$ rd), as well as ratings of disembodiment, $t(32)=-5.51, p<.001, d=1.18$, and difficulty, $t(32)=-5.04, p<.001, d=1.28$, (i.e., $3 \mathrm{rd}>1 \mathrm{st}$ ). No differences were observed between 3PS and 3PO on any of the measures. 
Figure 1. Behavioral ratings as a function of imagery perspective (1PS, 3PS, 3PO). A (pain) and B (vividness) show ratings made inside the scanner that were collected on a 5-point scale. C (disembodiment) and $\mathrm{D}$ (difficulty) show ratings made outside of the scanner that were collected on a 9-point scale. (Errors bars represent \pm 1 SEM).

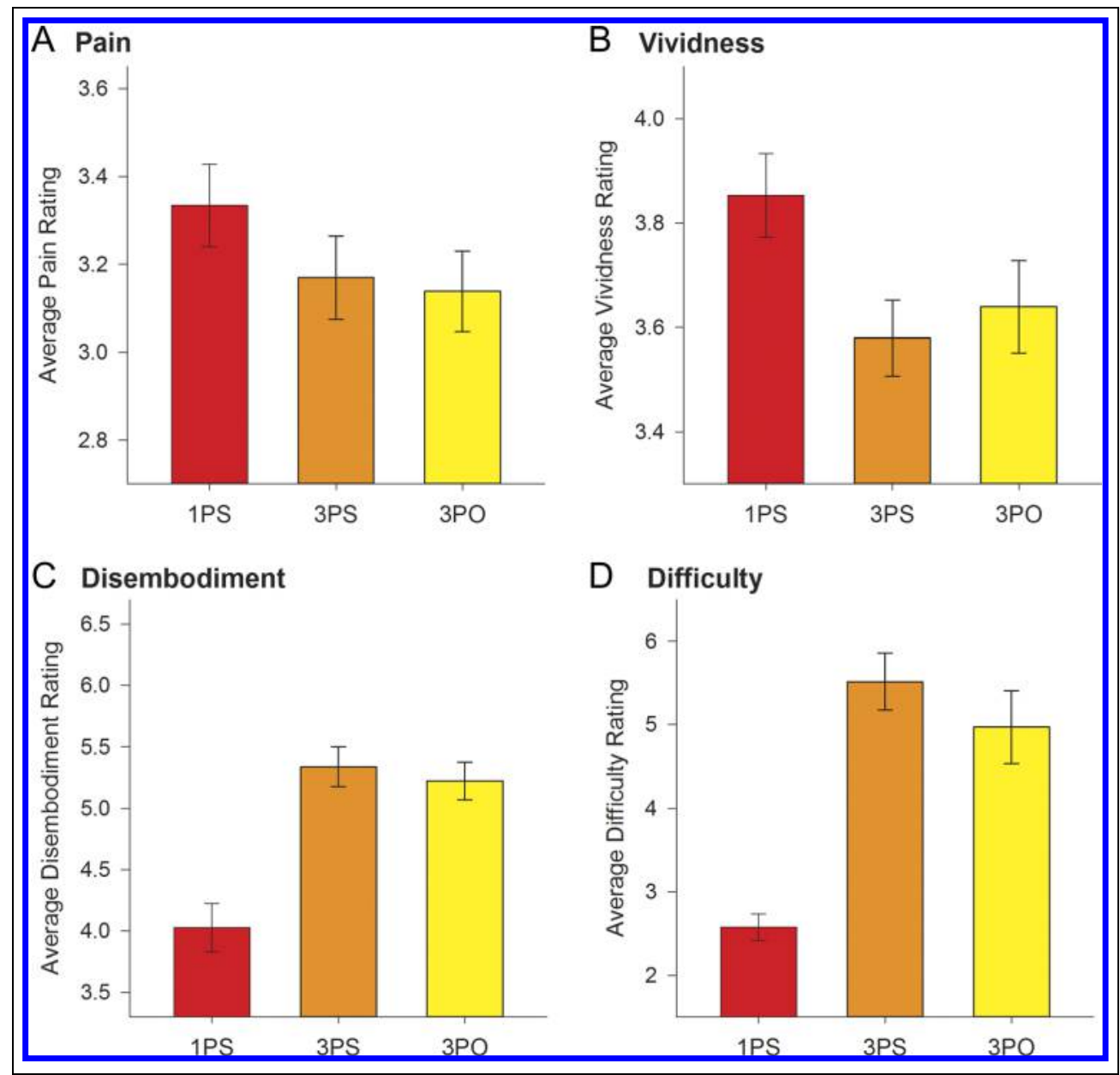

\section{Imaging Data}

Large clusters in the right AI (91 voxels; center of mass $[\mathrm{CoM}]=33,19,-15$; peak coordinate $=20,32,-16$; all coordinates reported in Talairach space) extending into the inferior and middle frontal gyri, the right inferior parietal lobe (IPL, 112 voxels; $\mathrm{CoM}=51,-53,33$; peak coordinate $=47,-68,42$ ) and left extrastriate cor- tex (90 voxels; CoM $-5,-90,7$; peak coordinate $=-8$, $-101,12)$ were more active for 1PS than for 3PS imagery after controlling for differences associated with the difficulty of the tasks (see Figure 2). A cluster in the right precuneus ( 72 voxels; $\mathrm{CoM}=12,-77,46$; peak coordinate $=$ $11,-83,48)$ approached but did not meet the minimum cluster extent (87 voxels) to survive the FWE-corrected significance threshold. This test revealed no brain areas

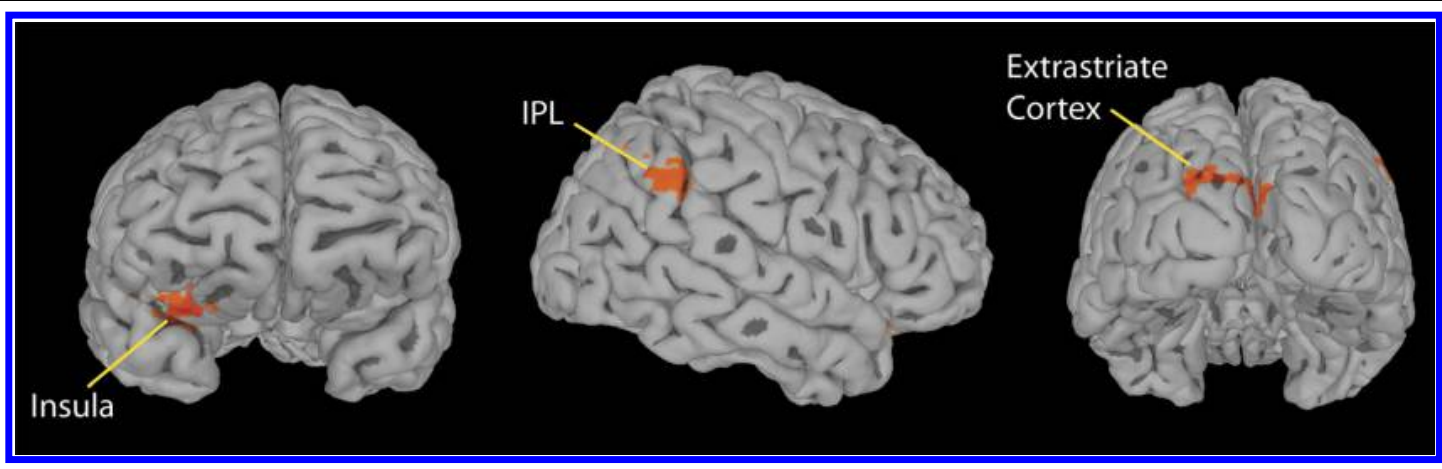

Figure 2. Clusters where 1PS $>3 \mathrm{PS}(p<.05$, FWE-corrected). From left to right: right AI ( 91 voxels; CoM $=33,19,-15$; peak coordinate $=20$, $32,-16)$, right IPL $(112$ voxels; $\mathrm{CoM}=51,-53,33$; peak coordinate $=47,-68,42)$, and left extrastriate cortex $(90$ voxels; CoM $-5,-90,7$; peak coordinate $=-8,-101,12)$. Results are presented on the AFNI TT_N27 template brain. 
that were preferentially recruited for 3PS compared with 1PS imagery.

Comparing 3PS and 3PO perspectives yielded no clusters that survived the FWE-corrected significance threshold. A cluster in the ventral MPFC (cluster extent $=$ 82 voxels; $\mathrm{CoM}=3,36,-16$; peak coordinate $=-5$, $35,-22$ ) was recruited more for $3 \mathrm{PO}$ than $3 \mathrm{PS}$ imagery but did not reach the minimum cluster size ( 87 voxels) to survive the FWE-corrected significance threshold. There were no clusters, even at reduced thresholds, which were more active for 3PS compared with 3PO imagery.

Interestingly, no significant differences were observed in BOLD responses during $1 \mathrm{PS}$ and $3 \mathrm{PO}$ imagery. The largest cluster at a voxel-wise threshold of $p<.02$ had an extent of only 52 voxels and spanned the right precuneus and posterior- to mid-cingulate cortex $(\mathrm{CoM}=$ $1,-33,43$; peak coordinate $=2,-32,45)$. A similar right AI cluster to that observed in the 1PS versus 3PS comparison also trended toward being recruited more for 1PS than for 3PO imagery $(\mathrm{CoM}=29,7,-16$; peak coordinate $=29,11,-22 ; 41$ voxels) but again did not reach the cluster extent threshold required to survive FWE correction. ${ }^{5}$

\section{DISCUSSION}

The current experiment utilized fMRI to investigate the effects of visual perspective on the neural and behavioral responses that accompany imagined sensory experiences (i.e., painful events). Focusing on a previously underexplored but regularly occurring perspective in the mental world (Christian et al., 2013; Sutin \& Robins, 2010; Nigro \& Neisser, 1983), the underlying neural mechanisms that support 3PS compared with 1PS and 3PO simulations were considered. Whole-brain contrasts revealed that 1PS simulations yielded greater activation than corresponding 3PS simulations in the right AI, right IPL, and left extrastriate cortex. In addition, 1PS simulations were considered to be more painful, more vivid, less difficult, and less disembodied than events imagined from a 3PS vantage point. Interestingly, no neural or behavioral differences emerged between 3PS and 3PO simulations.

Extending previous work on the vantage point differences that accompany self versus other imagery (Jackson et al., 2005, 2006; Decety \& Sommerville, 2003), the current results help to elucidate the neural and behavioral consequences of imagining self-relevant events from different viewpoints (see Lamm et al., 2011; Decety, 2010; Singer \& Lamm, 2009). Reflecting distinctions in the experiential nature of egocentric simulations (Macrae et al., 2013, 2014; Miles et al., 2014; Libby \& Eibach, 2011), 1PS simulations yielded greater activity in cortical regions associated with interoceptive and emotional awareness (i.e., AI; Lamm et al., 2011; Decety, 2010; Craig, 2003, 2009; Singer \& Lamm, 2009), psychological distance, body ownership (i.e., right IPL; Parkinson, Liu, \& Wheatley, 2014;
Decety \& Sommerville, 2003; Walsh, 2003), and visual imagery (i.e., extrastriate cortex; Kosslyn et al., 1996). Furthermore, 1PS accounts were judged to be more painful and body-centered than their 3PS equivalents. What this suggests is that self-relevance alone is not enough to give rise to a fully embodied experience.

These findings corroborate and extend the work of Eich and colleagues (2009), which identified neural mechanisms that support autobiographical recall of everyday actions viewed from either a first- or a third-person point of view. Similar to the current findings, limbic structures showed greater activation for first-person (cf. third-person) self-memory retrieval. Additionally, Eich et al. (2009) found that remembering in general (from either perspective) recruited a network of cortical regions (i.e., prefrontal and medial-temporal cortices, IPL, precuneus) more than a basic visual search control task. Interestingly, in the current study, the IPL and precuneus (although below threshold) did distinguish between first- and third-person imagery. Although speculative, an interesting question for future research will be to investigate the relationship between autobiographical memory and visual perspective to determine whether or not episodic content plays a more pronounced role in constructing hypothetical firstperson (cf. third-person) scenarios. It is possible that imagining events less dependent upon interoception and body awareness may reveal differences in the recruitment of other brain areas associated with self-referential processing, such as the MPFC (Wagner et al., 2012; Kelley et al., 2002).

\section{Vantage Point and Embodiment}

Through reactivation of the neural mechanisms that underlie veridical experience (e.g., Moulton \& Kosslyn, 2009; Kosslyn et al., 2006; Fadiga \& Craighero, 2004; Ganis et al., 2004; Grèzes \& Decety, 2001; Jeannerod, 2001), the imagination can elicit real-time physiological and emotional responses similar to those that accompany actual encounters (Holmes \& Mathews, 2010; Niedenthal et al., 2005; Barsalou, 1999). Consequently, mental simulations are invaluable informants about what the future might be like and the feelings it is likely to evoke (Boyer, 2008; Gilbert \& Wilson, 2007; Suddendorf \& Corballis, 2007; Wilson \& Gilbert, 2003). Considering the prevalence of a 3PS perspective in everyday life (Christian et al., 2013; Nigro \& Neisser, 1983), the present findings have a number of potential implications. To this end, richly embodied first-person imagery may be beneficial for certain forms of decision-making (e.g., selecting an entrée from a menu) that are reliant upon interoceptively rich simulations. However, there are undoubtedly occasions when physiological responses to mentally simulated events are problematic. Imagining, for instance, a life-threatening accident can leave a residue of negative affect long after the simulation has ended (Kosslyn et al., 1996; Sutherland \& Harrell, 1986; Roberts \& Weerts, 1982). 
Beyond instilling bad feelings, visceral responses to imaginary events also have the potential to fuel the symptoms of a range of psychological disorders (e.g., anxiety, social phobia, PTSD; see Holmes \& Mathews, 2010; Hirsch, Meynen, \& Clark, 2004; Shin et al., 1997; Pitman, Orr, Forgue, de Jong, \& Claiborn, 1987). A growing body of evidence has identified third-person self-imagery as an effective strategy for minimizing the unwanted consequences often associated with negatively tinged imaginary events (Kross, 2009; Williams \& Moulds, 2008; McIsaac \& Eich, 2004). Informing the effectiveness of this technique, the current work revealed that vantage point modulates recruitment of brain areas (e.g., AI) involved in interoception (Lamm et al., 2011; Singer \& Lamm, 2009; Hein \& Singer, 2008). Importantly, the human insula appears to be functionally organized along a posterior-to-anterior gradient. In contrast to the posterior insula, the AI is thought to support the subjective awareness of bodily states and emotions abstracted away from objective, modality-specific sensory inputs (Craig, 2009). During painful experiences, perceptions of intensity are reflected in AI responses (Peltz et al., 2011) even before stimulus onset (Ploner, Lee, Wiech, Bingel, \& Tracey, 2010; Wiech et al., 2010), suggesting that the AI may integrate information about salience into the subjective experience of pain. As such, preferential recruitment of the AI during 1PS imagery provides one potential mechanism by which 3PS simulations dull the awareness of sensory information that generally accompanies unpleasant imagined events.

Whereas comparable activity in the AI between 1PS and 3PO simulations did not meet threshold levels in the current study, previous research has demonstrated preferential recruitment of this and other canonical pain regions when imagining self versus other (Jackson et al., 2006). One potential reason for this inconsistency, aside from the highly intangible nature of the current task, is that in the present investigation each participant selected their own "other" target, ${ }^{3}$ whereas former studies have specifically dictated the "other" (e.g., the experimenter) that is to be imagined (Jackson et al., 2006). As such, the amount of variability in the 3PO condition here may be clouding differences in neural activity. Additionally, it is possible that individuals employ unique strategies when estimating the imaginary pain of a more personal "other" target. Although multiple approaches may ultimately converge on similar behavioral ratings (e.g., my pain is worse than your pain), they are likely to recruit distinct neural components (Lamm et al., 2011; Lamm \& Singer, 2010; Lamm, Batson, \& Decety, 2007). Future work will be necessary to explore these possibilities and probe the reliability of the subthreshold effects seen here. In so doing, it will be possible to determine the underlying neural mechanisms that support distinctions in behavioral assessments between 1PS and various $3 \mathrm{PO}$ targets.

Interestingly, in the current study, third-person simulations diminished pain ratings regardless of target (i.e., self vs. other) and no neural or behavioral differences distinguished between 3PS and 3PO simulations. Although caution should be taken when interpreting the absence of a significant difference, this pattern of results suggests that, when the self was imagined from a third-person point of view, it may have been represented in a manner comparable to that of simulating another person. Two strands of research would suggest that this might indeed be the case. First, as already noted, first-person simulations are more embodied than their third-person counterparts (Miles et al., 2014; Macrae et al., 2013; Kross, 2009; Lorey et al., 2009). Second, when going about our daily activities, body ownership, and the experience of self requires multisensory integration from a first-person frame of reference (e.g., Guterstam \& Ehrsson, 2012; Petkova et al., 2011; Tsakiris, 2010; Blanke \& Metzinger, 2008). Thus, when self-relevant episodes are imagined from a third-person vantage point, the simulated version of "me" may be stripped of the experiential components that produce the corporeal feeling of self (see Mitchell, Schirmer, Ames, \& Gilbert, 2011). Of course, future research will be needed to more directly consider the sense of self that accompanies 3PS simulations and to determine whether or not imagining events that are more self-reflective or social in nature reveals neural and behavioral distinctions between 3PS and 3PO that are not evident when simulating visceral states.

\section{Conclusion}

Guided by the observation that imagining the self from an outside point of view is a regular occurrence in the mental world (Christian et al., 2013; Sutin \& Robins, 2010; Nigro \& Neisser, 1983), the current study explored the underlying neural mechanisms that support 3PS simulations. When compared with 1PS, 3PS imagery reduced behavioral appraisals of pain and embodiment and attenuated BOLD responses in brain areas associated with monitoring subjective feeling states as well as psychological distance and body ownership. Further emphasizing the role of bodycentered simulations, the current study showed no neural or behavioral distinctions between 3PS and 3PO imagery. Future work will be required to determine if similar effects emerge when simulating events with alternative content and to probe the sense of self (or lack thereof) that accompanies 3PS simulations. Taken together, the present data demonstrated the role of vantage point as a critical determinant of the underlying mechanisms that support and the behavioral assessments that accompany imaginary sensory experiences_-even when they pertain exclusively to the "self."

Reprint requests should be sent to Brittany M. Christian, Booth School of Business, University of Chicago, 5807 S Woodlawn Ave., Chicago, IL 60637, or via e-mail: brittany.christian@ chicagobooth.edu. 


\section{Notes}

1. See Kross, Davidson, Weber, and Ochsner (2009) for a conceptually related study.

2. Scores on VVIQ $(1=$ perfectly clear, $5=$ no image at all $)$ were $M=1.99, S D=0.46$. Sixteen participants reported adopting a first-person perspective more often than a third-person perspective, whereas 17 reported the opposite pattern. With the goal of attenuating systematic differences in task difficulty between the two self-imagery conditions, we attempted to recruit approximately equivalent numbers of participants who reported naturally adopting first- and third-person perspectives during everyday self-imagery.

3. For the $3 \mathrm{PO}$ perspective, participants were instructed to think of a person who was their same gender and age, such as a classmate or coworker that they could clearly visualize, but not someone they knew well or would consider a good friend. This condition was called "third-other" throughout the course of the experiment and no instructions to adopt the other person's perspective, to empathize with them, or to put oneself in the other person's shoes were given. Of course, participants' natural tendencies to empathize with others, residual confusion about the task and idiosyncracies in the unfamiliar other they chose may have made for greater variation in participants' neural and behavioral responses for the "third-other" condition, thus contributing to the null findings.

4. Mauchly's test indicated that the assumption of sphericity had been violated for disembodiment ratings, $\chi^{2}(2)=10.77$, $p=.005$, and difficulty ratings, $\chi^{2}(2)=7.94, p=.019(\varepsilon=$ .81 and $\varepsilon=.85$ respectively); therefore, Huynh-Feldt corrected values are reported for these analyses.

5. In response to reviewers' comments, we also compared fMRI responses elicited by the $3 \mathrm{PO}$ imagery condition to those elicited by self-imagery, averaged across 1PS and 3PS imagery conditions. This contrast revealed no significant clusters that were differentially activated by the self- and other-imagery conditions.

\section{REFERENCES}

Addis, D. R., Wong, A. T., \& Schacter, D. L. (2007). Remembering the past and imagining the future: Common and distinct neural substrates during event construction and elaboration. Neuropsychologia, 45, 1363-1377.

Arnold, M. B. (1984). Imagery and psychophysiological response. Journal of Mental Imagery, 8, 143-150.

Barsalou, L. W. (1999). Perceptual symbol systems. Behavioral and Brain Sciences, 22, 577-660.

Blanke, O., \& Metzinger, T. (2008). Full-body illusions and minimal phenomenal selfhood. Trends in Cognitive Sciences, 13, 7-13.

Blanke, O., Mohr, C., Michel, C. M., Pascual-Leone, A., Brugger, P., Margitta, S., et al. (2005). Linking out-of-body experience and self processing to mental own-body imagery at the temporoparietal junction. The Journal of Neuroscience, 25, 550-557.

Blanke, O., Ortigue, S., Landis, T., \& Seeck, M. (2002). Neuropsychology: Stimulating illusory own-body perceptions. Nature, 419, 269-270.

Boyer, P. (2008). Evolutionary economics of mental time travel? Trends in Cognitive Sciences, 12, 219-224.

Buckner, R. L., \& Carroll, D. C. (2007). Self-projection and the brain. Trends in Cognitive Science, 11, 49-57.

Chaminade, T., \& Decety, J. (2002). Leader or follower? Involvement of the inferior parietal lobule in agency. NeuroReport, 13, 1975-1978.

Christian, B. M., Miles, L. K., Parkinson, C., \& Macrae, C. N. (2013). Visual perspective and the characteristics of mind wandering. Frontiers in Psychology, 4, 699.
Costantini, M., \& Haggard, P. (2007). The rubber hand illusion: Sensitivity and reference frame for body ownership. Consciousness and Cognition, 16, 229-240.

Cox, R. W. (1996). AFNI: Software for analysis and visualization of functional magnetic resonance images. Computers and Biomedical Research, 29, 162-173.

Craig, A. D. (2002). How do you feel? Interoception: The sense of the physiological condition of the body. Nature Review Neuroscience, 3, 655-666.

Craig, A. D. (2003). Interoception: The sense of the physiological condition of the body. Current Opinion in Neurobiology, 13, 500-505.

Craig, A. D. (2009). How do you feel-Now? The anterior insula and human awareness. Nature Review Neuroscience. 10, 59-70.

Critchley, H. D. (2004). The human cortex responds to an interoceptive challenge. Proceedings of the National Academv of Sciences. U.S.A., 101, 6333-6334.

Critchley, H. D. (2005). Neural mechanisms of autonomic, affective, and cognitive integration. Journal of Comparative Neurology, 493, 154-166.

Critchley, H. D. (2009). Psychophysiology of neural, cognitive and affective integration: fMRI and autonomic indicants. International Journal of Psychophysiology, 73, 88-94.

Critchley, H. D., Wiens, S., Rotshtein, P., Ohman, A., \& Dolan, R. J. (2004). Neural systems supporting interoceptive awareness. Nature Neuroscience, 7, 189-195.

de Vignemont, F., \& Singer, T. (2006). The empathic brain: How, when and why? Trends in Cognitive Sciences, 10, 435-441.

Decety, J. (1996). Do imagined and executed actions share the same neural substrate? Cognitive Brain Research, 3, 87-93.

Decety, J. (2010). The neurodevelopment of empathy in humans. Developmental Neuroscience, 32, 257-267.

Decety, J., \& Jackson, P. L. (2004). The functional architecture of human empathy. Behavioral Cognitive Neuroscience Reviews, 3, 71-100.

Decety, J., \& Jackson, P. L. (2006). A social-neuroscience perspective on empathy. Current Directions in Psvchological Science, 15, 54-58.

Decety, J., \& Sommerville, J. A. (2003). Shared representations between self and others: A social cognitive neuroscience view. Trends in Cognitive Sciences, 7, 527-533.

Derbyshire, S. W. (2000). Exploring the pain "neuromatrix." Current Review of Pain, 4, 467-477.

Ehrsson, H. H., Spence, C., \& Passingham, R. E. (2004). That's my hand! Activity in premotor cortex reflects feeling of ownership of a limb. Science, 305, 875-877.

Eich, E., Nelson, A. L., Leghari, M. A., \& Handy, T. C. (2009). Neural systems mediating field and observer memories. Neuropsychologia, 47, 2239-2251.

Fadiga, L., \& Craighero, L. (2004). Electrophysiology of action representation. Journal of Clinical Neuropbvsiology, 21, 157-169.

Farah, M. J. (1989). The neural basis of mental imagery. Trends in Neurosciences, 12, 395.

Farrer, C., \& Frith, C. D. (2002). Experiencing oneself vs. another person as being the cause of action: The neural correlates of the experience of agency. Neuroimage, 15, 596-603.

Gallese, V. (2005). Embodied simulation: From neurons to phenomenal experience. Phenomenology and Cognitive Science, 4, 23-48.

Ganis, G., Thompson, W. L., \& Kosslyn, S. M. (2004). Brain areas underlying visual mental imagery and visual perception: An fMRI study. Cognitive Brain Research, 20, 226-241. 
Gilbert, D. T., \& Wilson, T. D. (2007). Prospection: Experiencing the future. Science, 317, 1351-1354.

Grèzes, J., \& Decety, J. (2001). Functional anatomy of execution, mental simulation, observation and verb generation of actions: A meta-analysis. Human Brain Mapping, 12, 1-19.

Guterstam, A., \& Ehrsson, H. H. (2012). Disowning one's seen real body during an out-of-body illusion. Consciousness and Cognition, 21, 1037-1042.

Hein, G., \& Singer, T. (2008). I feel how you feel but not always: The empathic brain and its modulation. Current Opinion in Neurobiology, 18, 153-158.

Hirsch, C. R., Meynen, T., \& Clark, D. M. (2004). Negative self-imagery in social anxiety contaminates social interactions. Memory, 12, 496-506.

Holmes, E. A., \& Mathews, A. (2010). Mental imagery in emotion and emotional disorders. Clinical Psychologv Review, 30, 349-362.

Jackson, P. L., Brunet, E., Meltzoff, A. N., \& Decety, J. (2006). Empathy examined through the neural mechanisms involved in imagining how I feel versus how you feel pain. Neuropsvchologia, 44, 752-761.

Jackson, P. L., Meltzoff, A. N., \& Decety, J. (2005). How do we perceive the pain of others? A window into the neural processes involved in empathy. Neuroimage, 24, 771-779.

Jeannerod, M. (1994). The representing brain: Neural correlates of motor intention and imagery. Behavioral and Brain Sciences, 17, 187-245.

Jeannerod, M. (2001). Neural simulation of action: A unifying mechanism for motor cognition. Neuroimage, 14, S103-S109.

Kelley, W. M., Macrae, C. N., Wyland, C. L., Caglar, S., Inatia, S., \& Heatherton, T. F. (2002). Finding the self? An event-related fMRI study. Iournal of Cognitive Neuroscience, 14, 785-794.

Killingsworth, M. A., \& Gilbert, D. T. (2010). A wandering mind is an unhappy mind. Science, 330, 932.

Kosslyn, S. M., Ganis, G., \& Thompson, W. L. (2001). Neural foundations of imagery. Nature Reviews Neuroscience, 2, 635-642.

Kosslyn, S. M., Ganis, G., \& Thompson, W. L. (2006). Mental imagery and the human brain. In Q. Jing, M. R. Rosenzweig, G. D’Ydewalle, H. Zhang, H.-C. Chen, \& K. Zhang (Eds.), Progress in psychological science around the world, Vol. 1: Neural, cognitive and developmental issues (pp. 195-209). London: Psychology Press.

Kosslyn, S. M., \& Moulton, S. M. (2009). Mental imagery and implicit imagery. In K. D. Markman, W. M. P. Klein, \& J. A. Suhr (Eds.), Handbook of imagination and mental simulation (pp. 35-52). New York: Taylor \& Francis Group.

Kosslyn, S. M., Shin, L. M., Thompson, W. L., McNally, R. J., Rauch, S. L., Pitman, R. K., et al. (1996). Neural effects of visualizing and perceiving aversive stimuli: A PET investigation. NeuroReport, 7, 1569-1576.

Kross, E. (2009). When the self becomes other. Annals of the New York Academv of Sciences, 1167, 35-40.

Kross, E., Davidson, M., Weber, J., \& Ochsner, K. (2009). Coping with emotions past: The neural bases of regulating affect associated with negative autobiographical memories. Biological Psychiatry, 65, 361-366.

Lamm, C., Batson, C. D., \& Decety, J. (2007). The neural substrate of human empathy: Effects of perspective taking and cognitive appraisal. Journal of Cognitive Neuroscience 19, 42-58.

Lamm, C., Decety, J., \& Singer, T. (2011). Meta-analytic evidence for common and distinct neural networks associated with directly experienced pain and empathy for pain. Neuroimage, 54, 2492-2502.
Lamm, C., \& Singer, T. (2010). The role of the anterior insular cortex in social emotions. Brain Structure $\mathcal{E}$ Function, 241, 579-591.

Lawrence, E. J., Shaw, P., Giampietro, V. P., Surguladze, S., Brammer, M. J., \& David, A. S. (2006). The role of "shared representations" in social perception and empathy: An fMRI study. Neuroimage, 29, 1173-1184.

Lenggenhager, B., Mouthon, M., \& Blanke, O. (2009). Spatial aspects of bodily self-consciousness. Consciousness and Cognition, 18, 110-117.

Libby, L. K., \& Eibach, R. P. (2011). Visual perspective in mental imagery: A representational tool that functions in judgment, emotion, and self-insight. Advances in Experimental Social Psychology, 44, 185-245.

Lorey, B., Bischoff, M., Pilgramm, S., Stark, R., Munzert, J., \& Zentgraf, K. (2009). The embodied nature of motor imagery: The influence of posture and perspective. Experimental Brain Research, 194, 233-243.

Macrae, C. N., Christian, B. M., Golubickis, M., Karanasiou, M., Troksiarova, L., McNamara, D. L., et al. (2014). When do I wear me out? Mental simulation and the diminution of self-control. Journal of Experimental Psychologv: General. $143,1755-1764$

Macrae, C. N., Sunder Raj, R., Best, S. B., Christian, B. M., \& Miles, L. K. (2013). Imagined sensory experiences can shape person perception: It's a matter of visual perspective. Iournal of Experimental Social Psuchology, 49, 595-598.

Marks, D. F. (1973). Visual imagery differences in the recall of pictures. British Iournal of Psuchology, 64, 17-24.

McIsaac, H. K., \& Eich, E. (2002). Vantage point in episodic memory. Psvchonomic Bulletin E Review, 9, 144-150.

McIsaac, H. K., \& Eich, E. (2004). Vantage point in traumatic memory. Psvchological Science, 15, 248-253.

Meier, B. P., Schnall, S., Schwarz, N., \& Bargh, J. A. (2012). Embodiment in social psychology. Trends in Cognitive Science, 4, 705-716.

Miles, L. K., Christian, B. M., Masilamani, N., Volpi, L., \& Macrae, C. N. (2014). Not so close encounters of the third kind: Visual perspective and imagined social interaction. Social Psychological and Personality Science, 5, 558-565.

Mitchell, J. P., Schirmer, J., Ames, D. L., \& Gilbert, D. T. (2011). Medial prefrontal cortex predicts intertemporal choice. Iournal of Cognitive Neuroscience, 23, 1-10.

Moulton, S. T., \& Kosslyn, S. M. (2009). Imagining predictions: Mental imagery as mental emulation. Philosophical Transactions of the Royal Society, Series B, Biological Sciences, 364, 1273-1280.

Niedenthal, P. M., Barsalou, L. W., Winkielman, P., Krauth-Gruber, S., \& Ric, F. (2005). Embodiment in attitudes, social perception, and emotion. Personality and Social Psychologv Review. 9, $184-211$.

Nigro, G., \& Neisser, U. (1983). Point of view in personal memories. Cognitive Psychology, 15, 467-482.

Ochsner, K. N., Knierim, K., Ludlow, D. H., Hanelin, J., Ramachandran, T., Glover, G., et al. (2004). Reflecting upon feelings: An fMRI study of neural systems supporting the attribution of emotion to self and other. Iournal of Cognitive Neuroscience, 16, 1-27.

Ochsner, K. N., Zaki, J., Hanelin, J., Ludlow, D. H., Knierim, K. Ramachandran, T., et al. (2008). Your pain or mine? Common and distinct neural systems supporting the perception of pain in self and other. Social Cognitive and Affective Neuroscience, 3, 144-160.

Parkinson, C., Liu, S., \& Wheatley, T. (2014). A common cortical metric for spatial, temporal and social distance. Iournal of Neuroscience, 34, 1979-1987. 
Pavani, F., Spence, C., \& Driver, J. (2000). Visual capture of touch: Out-of-the-body experiences with rubber gloves. Psychological Science, 25, 353-359.

Peltz, E., Seifert, F., DeCol, R., Dörfler, A., Schwab, S., \& Maihöfner, C. (2011). Functional connectivity of the human insular cortex during noxious and innocuous thermal stimulation. Neuroimage, 54, 1324-1335.

Petkova, V. I., Khoshnevis, M., \& Ehrsson, H. H. (2011). The perspective matters! Multisensory integration in ego-centric reference frames determines full-body ownership. Frontiers in Psychology, 2, 35.

Pitman, R. K., Orr, S. P., Forgue, D. F., de Jong, J. B., \& Claiborn J. M. (1987). Psychophysiologic assessment of posttraumatic stress disorder imagery in Vietnam combat veterans. Archives of General Psvchiatrv, 44, 970-975.

Ploner, M., Lee, M. C., Wiech, K., Bingel, U., \& Tracey, I. (2010). Prestimulus functional connectivity determines pain perception in humans. Proceedings of the National Academv of Sciences, 107, 355-360.

Roberts, R. J., \& Weerts, T. C. (1982). Cardiovascular responding during anger and fear imagery. Psvchological Reports, 50, 219-230.

Ruby, P., \& Decety, J. (2001). Effect of the subjective perspective taking during simulation of action: A PET investigation of agency. Nature Neuroscience, 4, 546-550.

Schacter, D. L., Addis, D. R., \& Buckner, R. L. (2007). Remembering the past to imagine the future: The prospective brain. Nature Reviews Neuroscience, 8 , 657-661.

Shin, L. M., Kosslyn, S. M., McNally, R. J., Alpert, N. M., Thompson, W. L., Rauch, M. D., et al. (1997). Visual imagery and perception in posttraumatic stress disorder: A positron emission tomographic investigation. Archive of General Psvchiatrv, 54, 233-241.

Singer, T., Critchley, H. D., \& Preuschoff, K. (2009). A common role of insula in feelings, empathy and uncertainty. Trends in Cognitive Sciences, 13, 334-340.

Singer, T., \& Lamm, C. (2009). The social neuroscience of empathy. The Year in Cognitive Neuroscience 2009: Annals of the New York Academy of Sciences, 1156, 81-96.

Singer, T., Seymour, B., O’Doherty, J., Kaube, H., Dolan, R. J., \& Frith, C. D. (2004). Empathy for pain involves the affective but not sensory components of pain. Science 303, 1157-1162.

Smallwood, J., \& Schooler, J. W. (2006). The restless mind Psvchological Bulletin, 132, 946-958.

Smith, S. M., Jenkinson, M., Woolrich, M. W., Beckmann, C. F., Behrens, T. E. J., Johansen-Berg, H., et al. (2004). Advances in functional and structural MR image analysis and implementation as FSL. Neuroimage, 23, 208-219.

Suddendorf, T., \& Corballis, M. C. (2007). The evolution of foresight: What is mental time travel and is it unique to humans? Behavioral and Brain Sciences, 30, 299-351.
Sutherland, M., \& Harrell, J. (1986). Individual differences in physiological responses to fearful, racially noxious, and neutral imagery. Imagination. Cognition and Personality 6, 133-150.

Sutin, A. R., \& Robins, R. W. (2010). Correlates and phenomenology of first and third person memories. Memorv, 18, 625-637.

Szpunar, K. K. (2010). Episodic future thought: An emerging concept. Perspectives on Psychological Science, 5, 142-162.

Tsakiris, M. (2010). My body in the brain: A neurocognitive model of body-ownership. Neuropsvchologia, 48, 703-712.

Uddin, L. Q., Davies, M. S., Scott, A. A., Zaidel, E., Bookheimer, S. Y., Iacoboni, M., et al. (2008). Neural basis of self and other representation in autism: An fMRI study of self-face recognition. PLOS One, 3, e3526.

Van der Heiden, L., Scherpiet, S., Konicar, L., Birbaumer, N., \& Veit, R. (2013). Inter-individual differences in successful perspective taking during pain perception mediates emotional responsiveness in self and others: An fMRI study. Neuroimage, 65, 387-394.

Wagner, D. D., Haxby, J. V., \& Heatherton, T. F. (2012). The representation of self and person knowledge in the medial prefrontal cortex. Wilev Interdisciplinary Reviews: Cognitive Science, 3, 451-470.

Walsh, V. (2003). A theory of magnitude: Common cortical metrics of time, space and quantity. Trends in Cognitive Science, 7, 483-488.

Wegner, D. M., Sparrow, B., \& Winerman, L. (2004). Vicarious agency: Experiencing control over the movements of others. Iournal of Personality and Social Psvchology, 86, 838-848.

Wiech, K., Lin, C. S., Brodersen, K. H., Bingel, U., Ploner, M., \& Tracey, I. (2010). Anterior insula integrates information about salience into perceptual decisions about pain. Journal of Neuroscience, 30, 16324-16331.

Williams, A. D., \& Moulds, M. L. (2008). Manipulating recall vantage perspective of intrusive memories in dysphoria. Memorv, 16, 742-750.

Wilson, M. (2002). Six views of embodied cognition. Psychonomic Bulletin and Review, 9, 625-636.

Wilson, T. D., \& Gilbert, D. T. (2003). Affective forecasting. In M. P. Zanna (Ed.), Advances in experimental social psychology (pp. 345-411). San Diego, CA: Academic Press.

Zaki, J., Davis, J. I., \& Ochsner, K. N. (2012). Overlapping activity in anterior insula during interoception and emotional experience. Neuroimage, 62, 493-499.

Zaki, J., Ochsner, K. N., Hanelin, J., Wager, T. D., \& Mackey, C. (2007). Different circuits for different pain: Patterns of functional connectivity reveal distinct networks for processing pain in self and others. Social Neuroscience, 2, 276-291.

Zhang, Y., Brady, M., \& Smith, S. (2001). Segmentation of brain MR images through a hidden Markov random field model and the expectation-maximization algorithm. IEEE Transactions on Medical Imaging, 20, 45-57. 